\title{
Synthesis and evaluation of manganese dioxide with layered structure as an adsorbent for selective removal of strontium ions from aqueous solution
}

\author{
Yu. V. Bondar ${ }^{1}$ (i) S. A. Alekseev² ${ }^{2}$
}

Received: 29 April 2020 / Accepted: 4 July 2020 / Published online: 15 July 2020

(c) Springer Nature Switzerland AG 2020

\begin{abstract}
The selective removal of ${ }^{90} \mathrm{Sr}$ from natural waters and technological effluents is an important issue to ensure radiation safety. Manganese dioxide with layered structure was prepared through the reaction of potassium permanganate with manganese chloride in alkaline medium at room temperature. The results of $X$-ray diffraction method and Fourier transform infrared spectroscopy confirmed the formation of c-disordered hexagonal birnessite. Scanning electron microscopy revealed that the synthesized birnessite is formed as agglomerated microspheres. Scanning electron microscopy and adsorption-desorption method revealed that birnessite is formed as agglomerated microspheres with mesoporous texture and external surface area of $207 \mathrm{~m}^{2} / \mathrm{g}$. To determine the efficiency of the synthesized birnessite in selective removal of strontium ions from multicomponent solutions, the effect of contact time, competitive ions $(\mathrm{Na}, \mathrm{K}, \mathrm{Ca})$ and $\mathrm{pH}$ on strontium ions adsorption was investigated in detail. Strontium ions adsorption has demonstrated a fast initial adsorption followed by a much slower sorption process. It was found that the synthesized birnessite can effectively remove strontium ions from monocomponent solution. The presence of alkaline metals ions in the model solutions (up to $\sim 0.3 \mathrm{~mol} / \mathrm{l}$ ) had little effect on strontium ions adsorption; however, calcium ions caused considerable decrease in the adsorption parameters. However, taking into account a relatively high adsorption parameters obtained in the model solutions characterized by a high concentration of calcium ions and a significant excess of calcium over strontium ions, the synthesized birnessite can be considered as an adsorbent with a rather high selectivity toward strontium ions. It can be effectively applied for the removal of strontium ions from multicomponent solutions with a high salt content. The alkaline medium is preferable for selective removal of strontium ions. The synthesized birnessite has lots of additional advantages, such as its simple fabrication process, low-cost raw materials and the ease of desorption.
\end{abstract}

Keywords Manganese dioxide · Birnessite $\cdot$ Selective adsorption $\cdot$ Strontium-90 $\cdot$ Water decontamination

\section{Introduction}

Nuclear weapon tests, nuclear accidents or unauthorized release of radionuclides from nuclear facilities cause continuous increase in concentration of artificial radionuclides in the environment. ${ }^{90} \mathrm{Sr}$ is one of the most hazardous radioactive fission products owing to its long half-life period
(28.8 years), high solubility and biological toxicity. The results of extensive research have revealed that ${ }^{90} \mathrm{Sr}$ with ${ }^{137} \mathrm{Cs}$ radionuclides is among the most abundant radioactive pollutants in natural waters as well as in technological solutions; that is why, the selective removal of these radionuclides needs special attention to ensure radiation safety.

$\triangle$ Yu. V. Bondar, juliavad@yahoo.com | ${ }^{1}$ State Institution “The Institute of Environmental Geochemistry of National Academy of Sciences of Ukraine", 34a Palladin Ave., Kyiv 03142, Ukraine. ${ }^{2}$ Chemistry Department, Taras Shevchenko National University of Kyiv, Volodymyrska Street, 64, Kyiv 01601, Ukraine. 
Adsorption is the most effective and economically feasible method of purification of aqueous solutions containing trace amounts of $\mathrm{Sr}(\mathrm{II})$ ions [1, 2]. Synthetic inorganic adsorbents are the preferred materials for the removal of strontium radionuclides from natural waters and technological solutions due to their high selectivity, radiation and thermal stability. The widely used adsorbents are oxides/hydrated oxides of Ti(IV), Mn(IV), Zr(IV), $\mathrm{Sn}(\mathrm{IV})$, poly-antimony acids, crystalline titanates and silicotitanates, as well as various composites on their basis [1-5].

Manganese dioxide is considered as a promising material for the selective removal of strontium ions from multicomponent contaminated waters [6-12]. The term "manganese dioxide" (MD) in the scientific literature refers to a number of mineral species, the main structural unit of which is $\left[\mathrm{MnO}_{6}\right]$ octahedron (where $\mathrm{Mn}$ is represented predominantly by $\mathrm{Mn}^{4+}$ and $\mathrm{Mn}^{3+}$ ). These $\mathrm{MnO}_{6}$ octahedral units can be linked by edge- or corner-sharing in different ways to form crystals with layered (busserite, birnessite, etc.) or tunnel (cryptomelane, todorokite, etc.) structure [13].

There are many publications that show the high efficiency of manganese dioxide for ${ }^{90} \mathrm{Sr}$ removal from multicomponent solutions [2]. However, the correlation between the adsorption efficiency of manganese dioxide and its crystal structure is complicated by the fact that the authors have not paid enough attention to the identification of the manganese dioxide phase used. For example, several composite adsorbents containing manganese dioxide, defined as "manganese hydroxide," have demonstrated a high efficiency in the removal of ${ }^{90} \mathrm{Sr}$ from model solutions simulating low-level liquid radioactive waste [9] as well as radioactive waste waters from nuclear power plants with various surfactants [10].

Amorphous (hydrous) manganese oxide, extracted from soil samples, which have been collected in contaminated areas of Belarus, showed an accumulation of ${ }^{90} \mathrm{Sr}$ in the amounts exceeding the background by 5-10 times. Subsequent laboratory studies confirmed the high adsorption capacity of freshly synthesized hydrous manganese oxide samples with respect to ${ }^{90} \mathrm{Sr}$ at $\mathrm{pH}$ values from 4 to 9 [14]. It should be noted that the terms "amorphous" and "hydrous" manganese dioxide, as a rule, refer to the mineral named "birnessite" —manganese dioxide with layered structure. This mineral is formed in the form of fine-dispersed, poorly crystallized particles, the X-ray diffraction patterns of which show broad diffuse peaks.

Other publications inform on high selectivity of manganese dioxide samples with tunnel structure when sorbing ${ }^{90} \mathrm{Sr}$ from multicomponent solutions containing calcium and magnesium ions. For example, manganese dioxide adsorbent ISMA-3 (Russia) based on the mineral psilomelane (or cryptomelane) had the following separation coefficients: $\mathrm{Sr}-\mathrm{Ca}-23, \mathrm{Sr}-\mathrm{Mg}-650$ [6].

Other adsorbent ISM-S (Russia) based on manganese dioxide with the composition $(\mathrm{Na}, \mathrm{K})_{0.25-0.3} \mathrm{MnO}_{1.9-2.1}$ (apparently, cryptomelane) was successfully used for treatment of water from accumulating basin of the Mayak Production Association (Chelyabinsk Region, Russia) with high content of ${ }^{90} \mathrm{Sr}$. The initial ${ }^{90} \mathrm{Sr}$ activity was about $3.0 \times 10^{-8}$ $\mathrm{Ci} / \mathrm{l}$ and total water hardness of 4.5-5.4 meq/l [15].

The manganese dioxide samples with a tunnel structure (cryptomelane and todorokite), studied in [7], showed the selectivity coefficients $\mathrm{K}_{\mathrm{Sr} / \mathrm{K}}=1.0$ for cryptomelane and $\mathrm{K}_{\mathrm{Sr} / \mathrm{Mg}}=50.0, \mathrm{~K}_{\mathrm{Sr} / \mathrm{Ca}}=10$ for todorokite. It was mentioned also that todorokite is highly efficient in adsorption of other radionuclides $-{ }^{57} \mathrm{Co}$ (in the $\mathrm{pH}$ range of $1-10$ ) and

${ }^{137} \mathrm{Cs}$ (in acidic solutions).

Thus, the brief analysis of references indicates the high efficiency of manganese dioxide in the removal of ${ }^{90} \mathrm{Sr}$ from contaminated waters; however, it does not allow correlating the adsorption and selective to strontium ions properties with a certain crystalline structure of MD and requires additional research.

The aim of the present work is the synthesis of manganese dioxide with a layered structure (birnessite) and the determination of its efficiency in removal of strontium ions from mono- and multicomponent model solutions.

Later the obtained data will be compared with the adsorption properties of manganese dioxides with a tunnel structure (cryptomelane and todorokite) to answer the question on what manganese dioxide type has the best selectivity to strontium ions.

\section{Experimental}

\subsection{Materials and reagents}

Chemicals $\left(\mathrm{MnCl}_{2} \cdot 4 \mathrm{H}_{2} \mathrm{O}, \mathrm{KMnO}_{4}, \mathrm{NaNO}_{3}, \mathrm{KNO}_{3}, \mathrm{NaOH}\right.$, $\mathrm{KOH}$ ) were of analytical grade and used without additional purifications. Nonradioactive $\mathrm{SrCl}_{2} \times 6 \mathrm{H}_{2} \mathrm{O}$ (Dae Jung Chemicals \& Metals Co., Ltd., Siheung City, South Korea) was used as a surrogate for ${ }^{90} \mathrm{Sr}$ because of its identical chemical characteristics. All working solutions were prepared using distillated water; $\mathrm{pH}$ was adjusted with a suitable quantity of $\mathrm{NaOH}$ and $\mathrm{HCl}$, monitored with a digital $\mathrm{pH}$ meter. All adsorption experiments were carried out at ambient temperature.

\subsection{Synthesis of birnessite}

To synthesize birnessite, we used a redox chemical method involving the reaction between $\mathrm{Mn}$ (II) $\left(\mathrm{MnCl}_{2}\right.$ salt solution) and $\mathrm{Mn}(\mathrm{VII})$ ions $\left(\mathrm{KMnO}_{4}\right.$ salt solution) in alkaline medium 
( $\mathrm{KOH}$ solution, $\mathrm{pH} 9-10)$ at $\mathrm{KMnO}_{4} / \mathrm{MnCl}_{2}$ ratio of 0.56 [16]. The mixture was aged for $24 \mathrm{~h}$ at room temperature. Black precipitate was filtered under vacuum, washed several times with distilled water and then dried at $70^{\circ} \mathrm{C}$ for $24 \mathrm{~h}$. The obtained product was ground before the adsorption experiments.

\subsection{Characterization}

The surface morphology of the synthesized birnessite was observed by a JEOL JSM-6490LV scanning electron microscope (JEOL Ltd., Japan). The studied samples were sputter-coated with a thin Pt layer prior to examination. The scanning electron microscope (SEM) was equipped with an Oxford Instruments energy-dispersive $\mathrm{X}$-ray spectroscopy (EDS) system for analyzing elemental composition.

Fourier transform infrared (FTIR) measurements were taken using a Nicolet Nexus 470 FTIR spectrometer (Nicolet Instrument Corp.) with attenuated total reflectance mode.

X-ray diffraction (XRD) studies were carried out on a DRON-3 diffractometer (Scientific Industrial Enterprise "Burevestnik," St. Petersburg, Russia) using $\mathrm{Cu}-\mathrm{K}_{\mathrm{a}}$ radiation in the range $10^{\circ}-90^{\circ}$ in $2 \theta$ at room temperature.

The specific surface area, pore volume and nitrogen adsorption-desorption isotherm of the synthesized sample at liquid nitrogen temperature $\left(-196^{\circ} \mathrm{C}\right)$ were determined with the surface area analyzer Nova 2200e (Quantachrome, USA).

\subsection{Adsorption experiments}

A strontium chloride stock solution of $500 \mathrm{mg} / \mathrm{l}$ was diluted, as required, to obtain the desired concentration.

Adsorption experiments were carried out in batch mode under shaking by placing a dry ground birnessite sample $(0.05 \mathrm{~g})$ in a series of polypropylene flasks with $15 \mathrm{ml}$ of $\mathrm{SrCl}_{2}$ solution. After 24-h treatment, the residual solution was filtered through a Whatman filter paper and analyzed for $\mathrm{Sr}$ concentration by the atomic absorption spectrophotometer model AA-8500 (Nippon Jarrell-Ash Co., Ltd., Kyoto, Japan).

The amount of strontium ions adsorbed, or the adsorption capacity of the synthesized birnessite, $Q_{\mathrm{Sr}}(\mathrm{mg} / \mathrm{g})$, was calculated as follows:

$Q_{\mathrm{Sr}}=\frac{\left(C_{0}-C_{t}\right) \cdot V}{m}$

where $C_{0}$ and $C_{\mathrm{e}}$ are the initial concentration and concentration of strontium ions at time $t(\mathrm{mg} / \mathrm{l})$ in the experimental solution, $V$ is the volume of the solution $(\mathrm{l})$, and $W$ is the weight of the adsorbent $(\mathrm{g})$.
Adsorption efficiency $E_{\mathrm{Sr}}(\%)$ was calculated as follows:

$E_{\mathrm{Sr}}=\frac{C_{0}-C_{t}}{C_{0}} \cdot 100$

All the experiments were performed in duplicate.

\subsection{Desorption of strontium ions and repeated adsorption}

The desorption studies were carried out with $1 \mathrm{M} \mathrm{HCl}$ or $1 \mathrm{M} \mathrm{NH}_{4} \mathrm{NO}_{3}$ solution as the desorbing agent. A dry Srloaded birnessite sample $(0.05 \mathrm{~g})$ with the known amount of strontium ions adsorbed was put in a polypropylene flask with $15 \mathrm{ml}$ of desorbing solution. After 24-h treatment, the residual solution was filtered through a Whatman filter paper and analyzed for $\mathrm{Sr}$ concentration by the atomic absorption spectrophotometer.

The amount of strontium ions desorbed, $Q_{\text {D_sr }}(\mathrm{mg} / \mathrm{g})$, of the studied sample, was calculated as follows:

$Q_{D_{-} S r}=\frac{C_{D} \cdot V_{D}}{m_{D}}$

where $C_{D}$ is the concentration of Sr ions in the desorbing solution $(\mathrm{mg} / \mathrm{l}), V_{\mathrm{D}}$ is the volume of the desorbing solution $(\mathrm{l})$, and $m_{\mathrm{D}}$ is the weight of the studied sample (g).

Desorption efficiency $E_{\mathrm{D} \_s r}(\%)$ was calculated as follows:

$E_{D_{-} S r}=\frac{Q_{D_{\_} S r}}{Q_{S r}} \cdot 100$

The experimental conditions of the repeated adsorption were identical to those used in the first adsorption cycle.

The efficiency of the repeated adsorption (the adsorption retention) was calculated as a ratio of adsorption efficiency of the second (third....) adsorption cycle to adsorption efficiency of the first cycle.

At the end of adsorption as well as desorption experiments, the studied samples were washed with distilled water and dried at $70^{\circ} \mathrm{C}$ for $24 \mathrm{~h}$.

\section{Results and discussion}

\subsection{Birnessite synthesis}

Birnessite is a common name for hydrated layered manganese dioxides (phyllomanganates) formed by two-dimensional layers of edge-sharing $\left[\mathrm{MnO}_{6}\right]$ octahedra, with hydrated cations (e.g., $\mathrm{Na}^{+}, \mathrm{K}^{+}, \mathrm{Ca}^{2+}$ ) and water molecules in the interlayer region. The typical interlayer distance is close to $\sim 7 \AA$. Birnessite is a widely distributed in natural 
environments mineral, and it can be easily synthesized in laboratory conditions through various pathways [17]. Synthetic birnessite is formed as a porous fine-dispersed powder with high specific surface area (from dozens to hundreds of $\mathrm{m}^{2} / \mathrm{g}$ ) and a low point of zero charge $\sim 2-2.5$ [18].

Since the morphology and particles' size of synthetic birnessite have been shown to influence its sorption and oxidative properties [19], the synthesized mineral phase has been studied by SEM, EDS, FTIR and XRD methods.

The synthesized birnessite is a fine-dispersed black powder. SEM images show that birnessite is formed as rounded 20-30- $\mu \mathrm{m}$ particles (Fig. 1a); however, at a higher magnification it can be seen that the particles are agglomerates of smaller globules with a diameter of about 200-250 nm (Fig. 1b). Birnessite of similar morphology was reported in the literature [20]; however, it possible to find information on synthetic birnessite particles with other morphology too [19]. Microanalysis of the particles showed that they comprise such elements as $\mathrm{K}, \mathrm{Mn}$ and $\mathrm{O}$.

\subsection{Characterization of the synthesized birnessite}

As it is published in the scientific literature, the identification of both natural and synthetic birnessites is a challenge, since this mineral phase is formed as fine-dispersed poorly crystallized particles. The diffraction patterns show broad blurry peaks; that is why, birnessite is often named as amorphous or hydrous manganese dioxide. Only relatively recent detailed studies of a number of synthetic birnessites made it possible to distinguish two varieties, triclinic and hexagonal birnessite. It was also found that hexagonal birnessite can have both ordered and disordered along the $c$-axis structures $[16,21]$. The octahedral layers of synthetic triclinic and hexagonal birnessite were found to differ in Mn valence states and vacancy concentration that determines some difference in their chemical activity [22].
The X-ray diffractogram of the synthesized sample (Fig. 2) exhibits four broad asymmetric peaks at $2 \theta$ of $12.4^{\circ}$ ( $d$ spacing of $\left.7.2 \AA\right), 25.0^{\circ}\left(d \sim 3.6 \AA\right.$ ) $37.0^{\circ}(d \sim 2.5 \AA)$ and $65.6^{\circ}(d \sim 1.4 \AA)$. The position of the maxima and the intensity ratio of these peaks coincide well with that of disordered hexagonal birnessite, named as turbostratic birnessite $[16,21]$. All peaks are strongly broadened, indicating the presence of very small and/or poorly crystallized particles.

FTIR spectroscopy serves as a relatively simple technique for differentiating between manganese dioxides with layered and tunnel structure. It was established that a broad peak at $760 \mathrm{~cm}^{-1}$ is unique to the manganese dioxides with tunnel structure and assigned to an asymmetrical $\mathrm{Mn}-\mathrm{O}$ stretching vibration, corresponding to corner-sharing $\mathrm{MnO}_{6}$ octahedra [23]. This absorption band is absent in the FTIR spectrum of the synthesized birnessite (Fig. 3), and thus, it confirms the layered structure of the synthesized phase.

The FTIR spectrum of the synthesized birnessite displays the prominent absorption bands at $\sim 3300$ and $1635 \mathrm{~cm}^{-1}$ which are usually assigned to the $-\mathrm{OH}$ stretching vibration and banding vibration of molecular water,

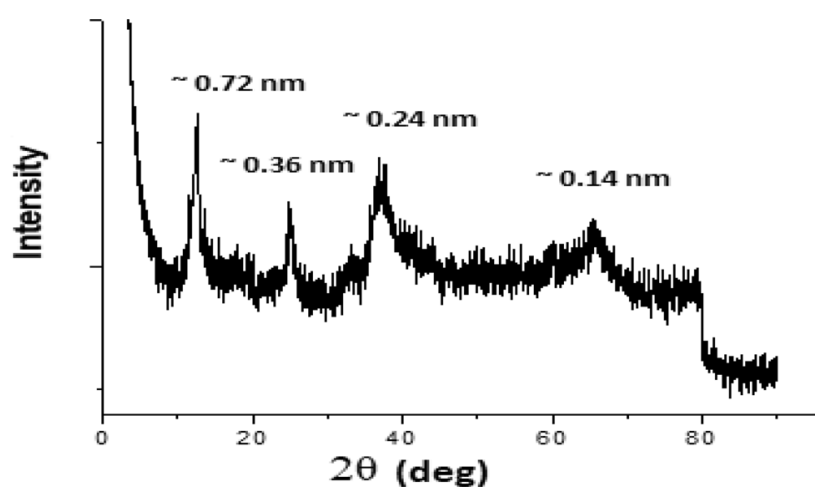

Fig. 2 Diffraction pattern of the synthesized birnessite

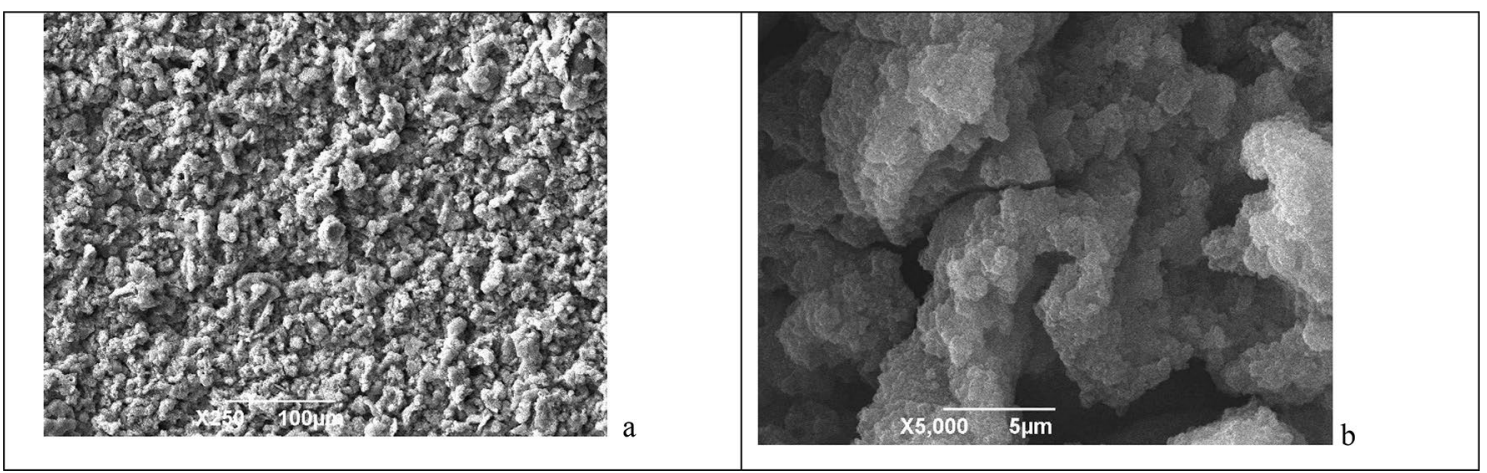

Fig. 1 SEM images of synthesized birnessite particles at different magnifications 


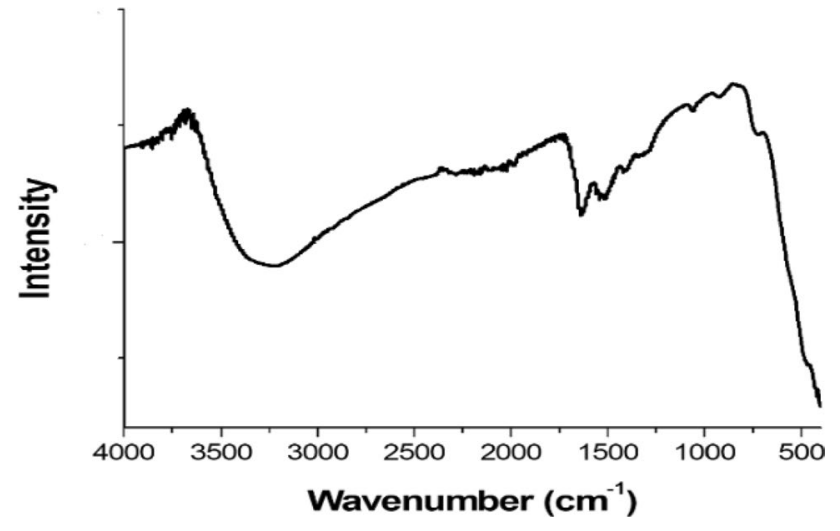

Fig. 3 FTIR spectra of the synthesized birnessite

correspondingly. These bands indicate the presence of crystal water in the birnessite structure. FTIR absorbances in the $400-900 \mathrm{~cm}^{-1}$ region represent contribution from $\mathrm{Mn}-\mathrm{O}$ stretching vibrations in the octahedral layers of manganese dioxides [22, 23]. The presented here FTIR spectrum is typical for hydrated layered manganese dioxides (phyllomanganates): relatively high contents of bound water, the presence of $\mathrm{OH}$-groups and bands that can be assigned to $\mathrm{Mn}-\mathrm{O}$ vibrations.

The nitrogen adsorption-desorption isotherms of the synthesized birnessite are shown in Fig. 4. A typical type-IVa isotherm with an $\mathrm{H} 3$ hysteresis loop is observed that points to the presence of a substantial amount of mesopores in the framework of the synthesized birnessite [24]. The specific surface area (BET method) and total pore volume calculated from the adsorption-desorption isotherms were $207 \mathrm{~m}^{2} / \mathrm{g}$ and $0.68 \mathrm{~cm}^{3} / \mathrm{g}$, correspondingly.

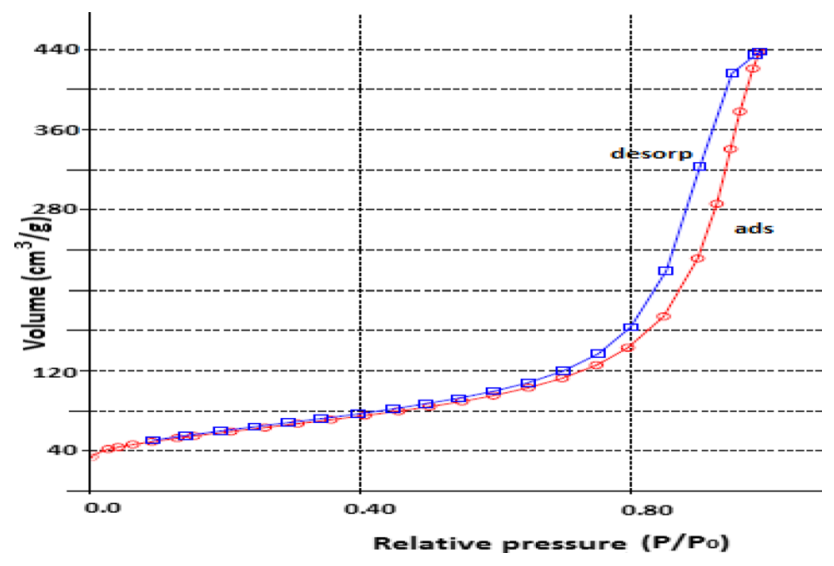

Fig. 4 Adsorption-desorption BET isotherms of the synthesized birnessite

\subsection{Strontium ions adsorption studies}

To determine the efficiency of the synthesized birnessite in selective removal of strontium ions from multicomponent solutions, the effect of contact time, competitive ions $(\mathrm{Na}, \mathrm{K}, \mathrm{Ca})$ and $\mathrm{pH}$ on strontium ions adsorption was investigated in detail.

\subsubsection{Effect of contact time on strontium ions adsorption}

Figure 5 shows the effect of contact time on the amount of strontium ions adsorbed by the synthesized birnessite. It can be seen that strontium adsorption is a twostep process; a half of the strontium ions presented in the solution were adsorbed within first $3 \mathrm{~h}$, and then the $Q_{\mathrm{Sr}}$ value slowly increased. It did not reach equilibrium over the duration of the study $(72 \mathrm{~h}$ ).

Trivedi and Axe [25] showed similar results for strontium ions adsorption on hydrous aluminum, iron and manganese oxides. Carrying out a long-term experiment (over 90 days), authors found that strontium adsorption on porous hydrous oxides can be described by a twostep process: rapid and reversible adsorption on the external surface followed by a much slower intraparticle diffusion and adsorption on interior sites. The second step was a diffusion-controlled process, and it could continue for several days or months before equilibrium is reached.

Comparable sorption behavior was also observed by authors in isotherms, where over several orders of magnitude a linear relationship between the amount of strontium ions adsorbed and the bulk strontium concentration in aqueous solutions was found suggesting one average type of site on the oxide surface.

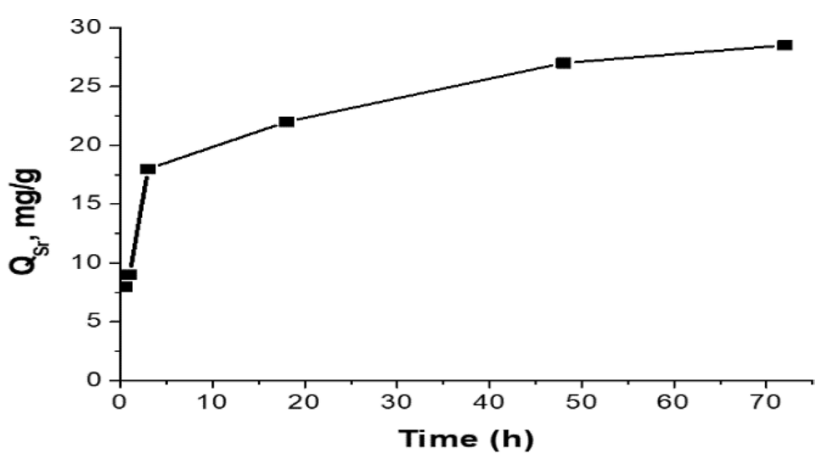

Fig. 5 Effect of contact time on the amount of Sr ions adsorbed by the synthesized birnessite. Initial concentration of strontium ions$1.44 \mathrm{mmol} / \mathrm{l} ; \mathrm{pH} \sim 6.5$ 


\subsubsection{Effect of concentration of competitive ions on strontium ion adsorption}

In this study, we considered the effect of sodium, potassium and calcium ions with respect to the adsorption of strontium ions because these ions are abundant in both seawater and freshwater, and $\mathrm{Na}, \mathrm{K}$ ions are the main chemical constituent in a typical evaporator concentrate from nuclear power plants. The effect of competitive ions concentration on the synthesized birnessite adsorption capacity was studied in five model solutions with neutral $\mathrm{pH}$ keeping the concentration of strontium ions constant ( $80 \mathrm{mg} / \mathrm{l}$ or $\sim 0.9 \mathrm{mmol} / \mathrm{l}$ ) and varying the concentration of other ions.

The first solution contained only strontium cations. The second along with strontium contained sodium cations $(0.1 \mathrm{~mol} / \mathrm{l})$. The third solution besides strontium contained sodium and potassium cations $(0.2$ and $0.1 \mathrm{~mol} / \mathrm{l}$, respectively). The fourth one contained strontium and calcium $(0.03 \mathrm{~mol} / \mathrm{l})$ cations with significant excess of calcium over strontium ions in the solution $(\mathrm{Ca} / \mathrm{Sr} \sim 33 / 1)$. The fifth solution contained strontium, calcium, sodium and potassium cations. The adsorption capacity of the synthesized birnessite was examined, and the obtained results are presented in Fig. 6.

One can see that the synthesized birnessite efficiently removes strontium ions from the first solution (adsorption capacity $\sim 24 \mathrm{mg} / \mathrm{g}$ and adsorption efficiency $\sim 99.8 \%$ ). In the second and third solutions with sodium and potassium ions, the adsorption capacity slightly decreases up to $21.6 \mathrm{mg} / \mathrm{g}\left(E_{\mathrm{Sr}} \sim 90 \%\right)$ and $21 \mathrm{mg} / \mathrm{g}\left(E_{\mathrm{Sr}} \sim 86 \%\right)$, respectively. It is obvious that an increase in the concentration of alkali metal ions in the solution from 0.1 to $0.3 \mathrm{~mol} / \mathrm{l}$ (the second and third solutions) does not cause a noticeable change in

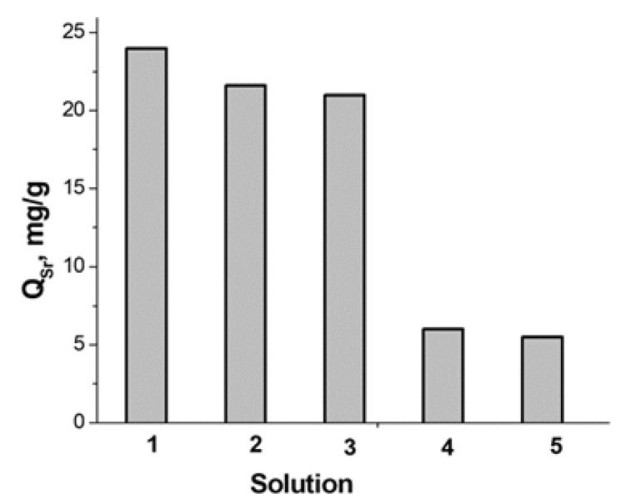

Fig. 6 Effect of competitive ions concentration on the adsorption capacity of strontium ions on the synthesized birnessite. Initial concentration of strontium ions $-0.9 \mathrm{mmol} / \mathrm{l} ; \mathrm{pH} \sim 6.5$. Solutions: $1 . \mathrm{Sr}$ ions; $2 . \mathrm{Sr}+\mathrm{Na}(0.1 \mathrm{~mol} / \mathrm{l})$ ions; $3 . \mathrm{Sr}+\mathrm{Na}(0.2 \mathrm{~mol} / \mathrm{l})+\mathrm{K}(0.1 \mathrm{~mol} / \mathrm{l})$ ions; $4 . \mathrm{Sr}+\mathrm{Ca}(0.03 \mathrm{~mol} / \mathrm{l})$ ions; $5 . \mathrm{Sr}+\mathrm{Ca}(0.03 \mathrm{~mol} / \mathrm{l})+\mathrm{Na}$ $(0.2 \mathrm{~mol} / \mathrm{l})+\mathrm{K}(0.1 \mathrm{~mol} / \mathrm{l})$ ions the adsorption parameters. This fact indicates that sodium and potassium ions in the concentrations used have no significant effect on the adsorption of strontium ions on the synthesized birnessite. In the fourth solution with the significant excess of calcium ions over strontium ions, the adsorption parameters of the synthesized birnessite are markedly reduced $\left(Q_{\mathrm{Sr}}-6.0 \mathrm{mg} / \mathrm{g}, E_{\mathrm{Sr}} \sim 25 \%\right.$, ). The reason is that strontium chemically resembles calcium, and therefore, these cations are competitors for available adsorption sites. The presence of sodium and potassium ions in the fifth solution with calcium ions does not have an additional effect on strontium ions adsorption $\left(Q_{\mathrm{Sr}_{\mathrm{r}}}-5.5 \mathrm{mg} / \mathrm{g}\right.$, $\left.E_{\mathrm{Sr}} \sim 23 \%\right)$.

The presented results testify that the synthesized birnessite can efficiently remove strontium ions; sodium and potassium ions have little effect on strontium ions adsorption, while the presence of calcium ions in the solution results in a significant decrease of the birnessite adsorption parameters. It should be noted, however, that calcium ion concentration in the model solutions $(0.03 \mathrm{~mol} / \mathrm{l}$, or $1200 \mathrm{mg} / \mathrm{l})$ is very high compared to that in tap water (2-85 mg/l) [26] and even higher than in seawater ( $470 \mathrm{mg} / \mathrm{l})$ [27]; that is why, the obtained rough results testify to the high efficiency of the synthesized birnessite in the removal of strontium ions from multicomponent solutions with high salt content.

The additional experiments to determine the effect of calcium on the adsorption parameters of the synthesized birnessite showed that its adsorption efficiency gradually decreases from 63 to $12.5 \%$ with increasing in calcium ions content in the model solutions from 0.01 to $0.06 \mathrm{~mol} / \mathrm{l}$.

The experimental results, indicating a significant effect of calcium ions on strontium ions adsorption, are presented in other publications. For example, Voronina et al. [2] collected and analyzed distribution coefficients of strontium $\left(K_{\mathrm{d}}\right)$ for a number of inorganic adsorbents, including those based on manganese dioxides. The presented data allow comparing distribution coefficients of strontium in the presence of high sodium and calcium concentrations in a solution. Seawater, $0.1 \mathrm{M} \mathrm{NaNO}_{3}$ and $0.01 \mathrm{M} \mathrm{CaCl}_{2}$ are the examples of these media. It was shown that most of the studied adsorbents demonstrate a high $K_{\mathrm{d}}$ value when sorbing radiostrontium from $0.1 \mathrm{M} \mathrm{NaNO}_{3}$; however, the presence of calcium ions in the solution leads to a sharp decrease in the $K_{\mathrm{d}}$ value for almost all adsorbents tested. The sorption material based on amorphous barium silicate $\left(\mathrm{BaSiO}_{3}\right)$ showed the highest selectivity for strontium over calcium ions in seawater- $K_{\mathrm{d}}=6.0 \times 10^{4}-6.4 \times 10^{3} \mathrm{ml} / \mathrm{g}$. Manganese dioxide-based adsorbents, including modified manganese dioxide adsorbent (MMD adsorbent, the structure has not been announced), ISM-S, and ISMA-3 demonstrated the distribution coefficient values of $1.4 \times 10^{3}$, 
$1.1 \times 10^{3}$ and $5.0 \times 10^{2} \mathrm{ml} / \mathrm{g}$ in $0.01 \mathrm{M} \mathrm{CaCl}_{2}$ solution, respectively. These values are higher than those for natural and synthetic zeolites $\left(1-3 \times 10^{2} \mathrm{ml} / \mathrm{g}\right)$, measured in $0.01 \mathrm{M} \mathrm{CaCl}_{2}$ solution.

To summarize the carried out adsorption studies, one can say that the synthesized birnessite can efficiently remove strontium ions; its adsorption capacity is little affected by sodium and potassium ions in the concentrations tested, while it decreases in the presence of Ca ions. However, taking into account a relatively high adsorption parameters obtained in the model solutions characterizing by a high concentration of calcium ions, the synthesized birnessite can be considered as an effective adsorbent for selective removal of strontium ions from multicomponent solutions.

\subsubsection{Effect of solution pH on strontium ions adsorption}

Strontium ions adsorption on the synthesized birnessite is greatly affected by solution $\mathrm{pH}$, since this parameter influences the birnessite surface charge and strontium ions species.

Strontium exists in aqueous solutions (without strong complexation anions) mainly as $\mathrm{Sr}^{2+}$ within a wide $\mathrm{pH}$ range, and above $\mathrm{pH} 13$, strontium ions form $\mathrm{Sr}(\mathrm{OH})^{+}$ species.

The point of zero charge (PZC) of birnessite is close to 2.5 [18]. The $\mathrm{PZC}$ determines the $\mathrm{pH}$ value where the electrical charge density on the birnessite surface is zero. When the $\mathrm{pH}$ is higher than 2.5, the birnessite surface becomes negatively charged and thus it could interact with positively charged strontium ions species and vice versa.

Assuming the surface hydroxyl groups are the adsorption sites, the effect of solution $\mathrm{pH}$ on strontium ions adsorption would be mostly determined by the protonation-deprotonation transition of these groups. As the $\mathrm{pH}$ increases from 2.5, the surface hydroxyl groups will be gradually deprotonated, so the arising negative surface charge would contribute to an increase in adsorption.

The effect of $\mathrm{pH}$ on strontium ions adsorption on the synthesized birnessite was studied in the model solution with the excess of calcium ions $(\mathrm{Ca} / \mathrm{Sr}=33 / 1)$. One can see (Fig. 7) that the adsorption capacity increases almost linearly from 2.4 to $9.6 \mathrm{mg} / \mathrm{g}$ with increasing $\mathrm{pH}$ from 3 to 9. The adsorption efficiency is $40 \%$ in the latter case that is 1.5 times higher than that in the neutral solution. Such behavior is typical for synthetic birnessite in sorption of alkali and alkali earth cations, and it has been described in many publications [28]. Thus, the experimental studies show that the alkaline medium is preferable for effective removal of strontium ions from multicomponent solutions.

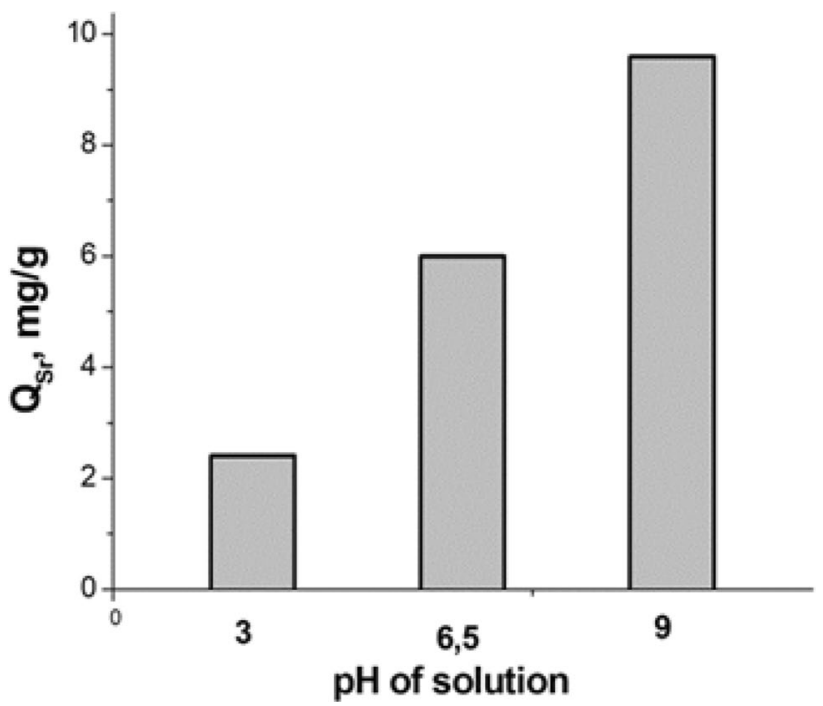

Fig. 7 Effect of $\mathrm{pH}$ on the adsorption capacity of strontium ions on the synthesized birnessite. Solution- $\mathrm{Sr}+\mathrm{Ca}$ ions $(0.9 \mathrm{mmol} / \mathrm{l}+0.03 \mathrm{~mol} / \mathrm{l})$

\subsubsection{Desorption of strontium ions and repeated adsorption}

Desorption is the process by which a contaminant bound on the loaded adsorbent can be released. Desorption is very important aspect of the adsorption process from an economic and technological point of view, as it allows regenerating the used adsorbent for another cycle of application and thus reducing the need for new ones. Otherwise, the technology for the loaded adsorbent disposal should be developed.

Strontium ions desorption was tested using $0.1 \mathrm{M} \mathrm{HCl}$ and $1 \mathrm{M} \mathrm{NH}_{4} \mathrm{NO}_{3}$ solutions as desorbing agents. To investigate the desorption processes and repeated adsorption (reusing), there were chosen three samples with almost identical amount of strontium ions adsorbed of 27.0, 27.5 и $27.8 \mathrm{mg} / \mathrm{g}$, correspondingly. The first and second samples were treated with $0.1 \mathrm{M} \mathrm{HCl}$ solution, and the third sample with $1 \mathrm{M} \mathrm{NH}_{4} \mathrm{NO}_{3}$ solution for desorption of strontium ions. After that, the first and third samples were used for the repeated adsorption, while the second one before the repeated adsorption was soaked in $0.5 \mathrm{M}$ $\mathrm{KCl}$ solution for $24 \mathrm{~h}$. The obtained results (Fig. 8) show that after 24-h treatment the adsorbed strontium ions were completely deleted by both desorbing agents.

As a result of the second adsorption, the amount of strontium ions adsorbed by the first sample was $7.1 \mathrm{mg} / \mathrm{g}$, by the second sample- $26.1 \mathrm{mg} / \mathrm{g}$, and by the third sample-26.9 $\mathrm{mg} / \mathrm{g}$. Compared to the first adsorption test, the efficiency of the repeated adsorption was 25,95 and $98 \%$, for the studied samples, correspondingly. 


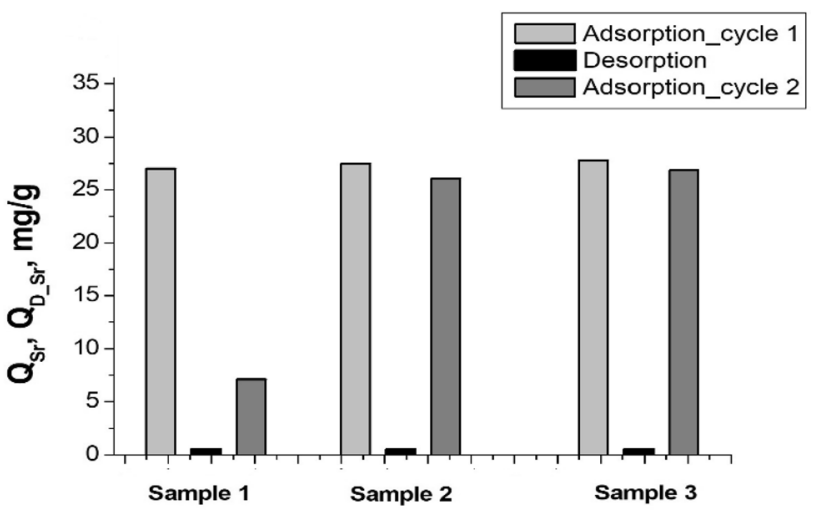

Fig. 8 Results of desorption and repeated adsorption tests. Adsorption tests: initial concentration of strontium ions $-1.44 \mathrm{mmol} / \mathrm{l}$; $\mathrm{pH} \sim 6.5$; adsorption time $48 \mathrm{~h}$

Low adsorption ability of the first sample after acid treatment seems to connect with the transition from K-hexagonal birnessite to its acid form (H-hexagonal birnessite). However, the reverse transition from $\mathrm{H}$-hexagonal birnessite to $\mathrm{K}$-form by soaking in $\mathrm{KCl}$ solution has led to restoring adsorption ability of the second sample.

Thus, among the tested desorbing agents, $1 \mathrm{M} \mathrm{NH}_{4} \mathrm{NO}_{3}$ solution is most preferable, because it is not required the additional stage (soaking in $\mathrm{KCl}$ ) for desorption and repeated adsorption cycles.

\section{Conclusions}

Synthetic birnessite prepared by the redox chemical method via the reaction between $\mathrm{Mn}(\mathrm{II})$ and $\mathrm{Mn}$ (VII) ions in alkaline medium is formed as black mesoporous agglomerated microspheres with surface area of $207 \mathrm{~m}^{2} / \mathrm{g}$.

The results of X-ray diffraction and FTIR analysis confirmed the formation of c-disordered hexagonal birnessite;

The batch adsorption experiments revealed that the synthesized birnessite could achieve an efficient adsorption of stable strontium ions from mono- and multicomponent aqueous solutions. It was shown that the presence of alkali metal ions in multicomponent solutions (up to $\sim 0.3 \mathrm{~mol} / \mathrm{l}$ ) has little effect on birnessite adsorption parameters, while the presence of $\mathrm{Ca}$ ions leads to their sharp decreases. However, taking into account the sufficiently high adsorption parameters obtained when sorbing from the model solutions with a significant excess of calcium over strontium ions, the synthesized birnessite can be considered as an adsorbent with a rather high selectivity to strontium ions;

Strontium adsorption kinetics has demonstrated a two-step process with initial fast step followed by a much slower sorption process;
The $\mathrm{pH}$ value in the model solutions has a major impact on the adsorption ability of the synthesized birnessite; a higher adsorption efficiency is obtained in an alkaline medium;

The desorption experiments demonstrated that $\mathrm{Sr}$ loaded birnessite could be regenerated successfully in $0.1 \mathrm{M} \mathrm{HCl}$ or $1 \mathrm{M} \mathrm{NH}_{4} \mathrm{NO}_{3}$ solutions; however, the latter solution was preferable one from economic and practical viewpoint.

In summary, the synthesized c-disordered hexagonal birnessite (manganese dioxide with layered structure) is an effective material for the removal of strontium ions from multicomponent solutions with high salt content. It has lots of advantages, such as its simple fabrication process, low-cost raw materials and the ease of desorption. It might be potentially applied as an active sorbing phase of the composite adsorbents that would extend the use of the latter in various fields.

Acknowledgements The authors express their gratitude to Slyvinsky V.M. for his help in SEM analysis and to Kuzenko S.V. for her help in strontium ions measurements.

\section{Compliance with ethical standards}

Conflict of interest The authors declare that there is no any conflict of interest regarding the publication of this article.

\section{References}

1. Myasoedova GV, Nikashina VA (2006) Absorbent materials for extracting radionuclides from aqueous media. Rus Chem J 50(5):55-63 (in Russian)

2. Voronina AV, Semenishchev VS, Dharmendra KG (2020) Use of sorption method for strontium removal. In: Pathak P, Gupta DK (eds) Strontium contamination in the environment. Springer, Cham, pp 203-226. https://doi.org/10.1007/978-3-030-15314 $-4 \_11$

3. Sylvester P, Clearfield A (1998) The removal of strontium and cesium from simulated Hanford groundwater using inorganic ion exchange materials. Solv Extr lon Exch 16(6):15271539. https://doi.org/10.1080/07366299808934593

4. Lehto J, Brodkin L, Harjula R, Tusa E (1999) Separation of radioactive strontium from alkaline nuclear waste solutions with the highly effective ion exchanger SrTreat. Nucl Technol 127(1):81-87

5. Avramenko VA, Egorin AM, Papynov EK, Sokol'nitskaya TA, Tananaev IG, Sergienko VI (2017) Processes for treatment of liquid radioactive waste containing seawater. Radiochemistry 59(4):407-413. https://doi.org/10.1134/S1066362217040142

6. Leontieva GV (1997) Structural modification of manganese (III, IV) oxides in synthesis of sorbents selective for strontium. Russ J Appl Chem 70:1615-1618

7. Dyer A, Pillinger M, Newton J et al (2000) Sorption behavior of radionuclides on crystalline synthetic tunnel manganese oxides. Chem Mater 12(12):3798-3804. https://doi.org/10.1021/cm001 $142 \mathrm{v}$ 
8. Kirillov SA, Lisnycha TV, Pendeluk OI (2006) Appraisal of mixed amorphous manganese oxide/titanium oxide sorbents for the removal of strontium-90 from solutions, with special reference to Savannah river site and Chernobyl radioactive waste simulants. Adsorpt Sci Technol 24(10):895-906. https://doi. org/10.1260/026361707781421979

9. Valsala TP, Joseph A, Sonar NL et al (2010) Separation of strontium from low level radioactive waste solutions using hydrous manganese dioxide composite materials. J Nucl Mater 404:138143. https://doi.org/10.1016/j.jnucmat.2010.07.017

10. Oh S, Shin WS, Choi SJ (2015) Hydrous manganese oxide-polyacrylonitrile (HMO-PAN) composite for the treatment of radioactive laundry wastewater. J Radioanal Nucl Chem 303:495-508. https://doi.org/10.1007/s10967-014-3583-2

11. Ivanets Al, Katsoshvili LL, Krivoshapkin PV, Prozorovich VG, Kuznetsova TF, Krivoshapkina EF, Radkevich AV, Zarubo AM (2017) Sorption of strontium ions onto mesoporous manganese oxide of OMS-2 type. Radiochemistry 59:264-271. https://doi. org/10.1134/S1066362217030080

12. Krivoshapkin PV, Ivanets Al, Torlopov MA, Mikhaylov VI et al (2019) Nanochitin/manganese oxide-biodegradable hybrid sorbent for heavy metal ions. Carbohydr Polym 210:135-143. https://doi.org/10.1016/j.carbpol.2019.01.045

13. Post JE (1999) Manganese oxide minerals: crystal structures and economic and environmental significance. Proc Natl Acad Sci USA 96:3446-3454. https://doi.org/10.1073/pnas.96.7.3447

14. Kuznetsov VA, Generalova VA (2000) The study of sorption properties of iron, manganese, titanium, aluminum and silicone oxides with respect to ${ }^{90} \mathrm{Sr}$ and ${ }^{137} \mathrm{Cs}$. Radiochemistry 42(2):166-169

15. Voroshilov YA, Logunov MV, Prokof'ev NN et al (2003) ISM-S sorbent: properties and tests in a sorption process for treatment of water from accumulating basin of the Mayak production association to remove ${ }^{90} \mathrm{Sr}$. Radiochemistry 45(1):64-67. https://doi. org/10.1023/A:1022325703593

16. Villalobos M, Toner B, Bargar J, Sposito G (2003) Characterization of the manganese oxide produced by Pseudomonas putida strain MnB1. Geochim Cosmochim Acta 67(14):2649-2662. https ://doi.org/10.1016/S0016-7037(03)00217-5

17. Boumaiza H, Coustel R, Medjahdi G et al (2017) Conditions for the formation of pure birnessite during the oxidation of $\mathrm{Mn}$ (II) cations in aqueous alkaline medium. J Solid State Chem 248:1825. https://doi.org/10.1016/j.jssc.2017.01.014

18. McKenzie RM (1981) The surface charge on manganese dioxides. Aust J Soil Res 19(1):41-50. https://doi.org/10.1071/SR9810041
19. Villalobos M, Escobar-Quiroz IN, Salazar-Camacho C (2014) The influence of particle size and structure on the sorption and oxidation behavior of birnessite: I. Adsorption of $\mathrm{As}(\mathrm{V})$ and oxidation of As(III). Geochim Cosmochim Acta 125:564-581. https:// doi.org/10.1016/j.gca.2013.10.029

20. Ghaly M, El-Dars F, Hegazy MM, Abdel Rahman R (2016) Evaluation of synthetic birnessite utilization as a sorbent for cobalt and strontium removal from aqueous solution. Chem Eng J 284:1373-1385. https://doi.org/10.1016/j.cej.2015.09.025

21. Drits VA, Lanson B, Gaillot AC (2007) Birnessite polytype systematics and identification by powder X-ray diffraction. Am Mineral 92(5-6):771-788. https://doi.org/10.2138/am.2007.2207

22. Ling FT, Post JE, Heaney PJ, Ilton ES (2018) The relationship between $\mathrm{Mn}$ oxidation state and structure in triclinic and hexagonal birnessites. Chem Geol 479:216-227. https://doi. org/10.1016/j.chemgeo.2018.01.011

23. Kang L, Zhang M, Liu ZH et al (2007) IR spectra of manganese oxides with either layered or tunnel structures. Spectrochim Acta Part A 67(3-4):864-869. https://doi.org/10.1016/j. saa.2006.09.001

24. Thommes M, Kaneko K, Neimark AV, Olivier JP, Rodriguez-Reinoso F et al (2015) Physisorption of gases, with special reference to the evaluation of surface area and pore size distribution (IUPAC Technical Report). Pure Appl Chem 87(9-10):1051-1069. https://doi.org/10.1515/pac-2014-1117

25. Trivedi P, Axe $L$ (1999) A comparison of strontium sorption to hydrous aluminum, iron, and manganese oxides. J Colloid Interface Sci 218:554-563. https://doi.org/10.1006/jcis.1999.6465

26. Ong CN, Grandjean AC, Heaney RP (2009) The mineral composition of water and its contribution to calcium and magnesium intake. In: Cotruvo J, Bartram J (eds) Calcium and magnesium in drinking-water: public health significance. World Health Organization, Geneva, pp 36-56

27. Krumgalz BS (1982) Calcium distribution in the world ocean waters. Oceanol Acta 5(1):121-128

28. Appelo CAJ, Postma DA (1999) A consistent model for surface complexation on birnessite $\left(\delta-\mathrm{MnO}_{2}\right)$ and its application to a column experiment. Geochim Cosmochim Acta 63(19/20):30393048. https://doi.org/10.1016/S0016-7037(99)00231-8

Publisher's Note Springer Nature remains neutral with regard to jurisdictional claims in published maps and institutional affiliations. 